www.scientiaplena.org.br

\title{
Análise de impactos na saúde pela implantação de Melhorias Sanitárias Domiciliares em Itabaiana/SE
}

Analysis of health impacts through the implementation of sanitary household improvements in Itabaiana/SE

\author{
T. A. Barbosa ${ }^{1 *}$; L. C. Mendonça ${ }^{2}$ \\ ${ }^{I}$ Departamento de Engenharia Civil/Mestranda do curso de Pós-Graduação em Engenharia Civil, Universidade \\ Federal de Sergipe, Av. Marechal Rondon, S/N - Rosa Elze - 49000-100, São Cristóvão-Sergipe, Brasil \\ ${ }^{2}$ Departamento de Engenharia Civil/Professora Doutora do curso de Engenharia Civil, Universidade Federal de \\ Sergipe, Av. Marechal Rondon, S/N - Rosa Elze - 49000-100, São Cristóvão-Sergipe, Brasil
}

*taisacivil@gmail.com

(Recebido em 26 de maio de 2017; aceito em 30 de setembro de 2017)

\begin{abstract}
No Brasil, a insuficiência dos serviços de saneamento básico, principalmente no que diz respeito à coleta $\mathrm{e}$ ao tratamento dos esgotos, pode estar relacionada aos elevados índices de doenças infecciosas e parasitárias. Esse estudo teve o propósito de analisar a associação entre essas doenças e o saneamento básico através da avaliação de dados de uma região beneficiada com o programa, Melhorias Sanitárias Domiciliares (MSD), da Fundação Nacional de Saúde (Funasa) em comunidades carentes. Para esse estudo, foram estudadas comunidades do município de Itabaiana, Sergipe, as quais tiveram o convênio com a Funasa concluído em 2010, o que possibilitou a caracterização da situação epidemiológica antes e depois dessas intervenções. Essa caracterização foi realizada através de dados fornecidos pela Funasa, órgãos de saúde e através de questionário elaborado durante a pesquisa com entrevistas porta a porta. As taxas de doenças infectoparasitárias diminuíram, com exceção da dengue, que obteve um leve aumento. Entretanto, notou-se que esse acréscimo aconteceu, provavelmente, por outros fatores que não os diretamente ligados à falta de saneamento básico. Concluiu-se que as intervenções sanitárias de fato impactaram positivamente na saúde da população beneficiada com o programa.

Palavras-chave: saneamento e saúde, esgotamento sanitário, doenças infecciosas e parasitárias.
\end{abstract}

In Brazil, an insufficiency of basic sanitation services, mainly in relation to sewage collection and treatment, may be related to the high rates of infectious and parasitic diseases. The aim of this study was to analyze an association between diseases and basic sanitation through the evaluation of data from a benefited poor community with a national health foundation program, called Sanitary Household Improvements. For this study, the communities of the municipality of Itabaiana, Sergipe, were adopted. Their agreement with the national health foundation completed in 2010 , which made it possible to characterize the epidemiological situation before and after the interventions. This research was performed through data collected with the foundation, health agencies and a questionnaire carried out with door to door interviews. As a result, the rates of infectious diseases decreased, except dengue, which increased slightly. However, it was noted that this increase may be due to other factors that are not directly related to lack of basic sanitation. Finally, it was concluded that the sanitary interventions actually had a positive impact on the people benefited by the program.

Keywords: sanitation and health, sanitary sewage, infectious and parasitic diseases.

\section{INTRODUÇÃO}

Entende-se por saneamento básico as atividades que visam à proteção da saúde da população por meio de serviços de abastecimento de água, coleta e tratamento de esgoto, manejo de resíduos sólidos, limpeza urbana, sistemas de drenagem e controle de agentes patogênicos [1].

O desenvolvimento de uma sociedade está atrelado ao saneamento básico, pois este causa impactos ao meio ambiente, bem-estar e saúde das pessoas. Estudos recentes vêm mostrando que 
investir em serviços de saneamento básico ajuda, de forma bastante eficiente, a reduzir os índices de diversas doenças [2].

A eficiência dos investimentos com saneamento básico em relação à saúde está principalmente atrelada ao caráter preventivo dessa ação. Isto é, a implementação de infraestrutura sanitária atuando como prevenção de doenças traz benefícios superiores aos adquiridos através de investimentos em assistência médica [3].

Dessa forma, esse estudo analisou os resultados advindos de intervenções sanitárias realizadas pela Fundação Nacional de Saúde (Funasa) [4] em comunidades anteriormente desprovidas de esgotamento sanitário, de modo a verificar o impacto direto dessas ações e, possivelmente, contribuir para a análise da eficácia do programa, da necessidade de ampliar as áreas de atendimento ou da necessidade por adaptações.

\section{MATERIAL E MÉTODOS}

A fim de atingir os objetivos propostos, o presente trabalho buscou, inicialmente, desenvolver um embasamento teórico a respeito das condições de saneamento no Brasil e em Sergipe, observando-se a abrangência desses serviços e os impactos entre os sistemas de saneamento básico e a saúde das pessoas.

Em seguida, levantamentos foram realizados na Funasa, na seção Sergipe, para conhecer detalhadamente os projetos das Melhorias Sanitárias Domiciliares (MSD) executadas em alguns povoados de Itabaiana. Tratava-se basicamente da construção de módulos sanitários externos, compreendendo as instalações básicas para banheiro; reservatório elevado de fibrocimento, sem amianto; e um sistema de tanque séptico e sumidouro. As informações sobre o projeto, a descrição dos serviços, o tempo de execução e os croquis com a identificação dos domicílios atendidos foram coletados nas visitas à Funasa.

Além disso, pesquisas foram realizadas na plataforma digital do Departamento de Informática do SUS - DATASUS (2016) [5] e na Secretaria de Saúde de Itabaiana buscando-se conhecer as características epidemiológicas dos povoados beneficiados pelo programa. Todavia, isso não foi possível uma vez que esses órgãos apenas possuíam indicadores do município Itabaiana como um todo, o qual, segundo projeção divulgada pelo IBGE (2010) [6], possui mais de 90 mil habitantes, e as MSD foram implantadas apenas em alguns povoados específicos, contabilizando um total de 190 residências.

Por outro lado, essas pesquisas possibilitaram o reconhecimento das doenças que ocorriam com mais frequência naquela região, e serviu como base para o desenvolvimento do questionário que foi, posteriormente, usado nas entrevistas com as famílias beneficiadas. A análise estatística para aplicação do questionário, por sua vez, foi realizada através do método de Triola (2013) [7], o qual é indicado para população finita e relativamente pequena.

O questionário elaborado na pesquisa procurou conhecer a composição das famílias e a proporção de crianças nos domicílios. Além disso, tinha o objetivo de colher informações quanto aos benefícios gerados, dificuldades encontradas, satisfação da população objetivo e, por fim, buscava levantar dados sobre a frequência que as pessoas tinham sido contaminadas pelas doenças infecciosas e parasitárias mais constantes (diarreia, dengue, esquistossomose e hepatite viral) no período anterior e posterior às melhorias sanitárias.

\section{RESULTADOS E DISCUSSÃO}

O cálculo inicial do tamanho da amostra, segundo Triola (2013) [7], apontava para a necessidade de aplicar o questionário em 50 domicílios. Esse cálculo foi feito considerando-se alguns parâmetros teóricos, como nível de confiança correspondente a 95\% e erro amostral de $10 \%$. Comparativamente, utilizando-se o método de Barbetta (2006) [8] para calcular o tamanho da amostra, a amostragem para um erro de $10 \%$ seria de 65 domicílios. No entanto, diversos problemas ocorreram durante o estudo, possibilitando apenas a realização de 34 entrevistas.

Os problemas estavam essencialmente relacionados com dificuldade em encontrar os domicílios beneficiados. Mesmo com os croquis disponibilizados pela Funasa, os quais possuíam a 
enumeração das casas e a identificação de alguns pontos de referência, os domicílios se encontravam em povoados rurais com pouca ou nenhuma sinalização e em arruamentos que não são identificados. Ou seja, apenas as casas localizadas próximas aos pontos de referência eram facilmente reconhecidas.

Além disso, a existência de novos moradores em algumas casas eliminou a possibilidade de entrevista, já que o objetivo do estudo foi analisar se houve uma melhora nas condições de saúde após a construção dos módulos sanitários e, para isso, seria necessário que a família residisse no local desde antes. Dessa maneira, com a aplicação do questionário em somente 34 residências, o estudo acabou obtendo um erro amostral de $12,8 \%$. Isto é, maior que o desejado e indicado pela literatura.

Analisando-se os dados foi possível fazer a composição da população atendida, a qual é predominantemente composta por adultos $-63 \%$. No entanto, durante as entrevistas percebeu-se uma grande presença de crianças que permaneciam nas casas durante o dia, mas não necessariamente residiam nelas, apontando para um risco maior de contaminação para essas crianças que andavam descalças e se divertiam próximo a áreas com esgoto a céu aberto. Segundo a World Health Organization, WHO (2013) [9], a defecação ao ar livre é uma grande preocupação em algumas regiões, uma vez que afeta diretamente as taxas de mortalidade infantil.

Os resultados quanto à satisfação mostraram também que a construção dos módulos sanitários nas áreas externas das casas e a implementação de sistema fossa-sumidouro foram bem recebidos pelas famílias, as quais se mostraram amplamente entusiasmadas com as mudanças.

Os benefícios quanto à saúde puderam ser notados na redução dos índices de diarreia, esquistossomose e hepatite viral, como pode ser visto comparando-se as Figuras 1 e 2.

De acordo com as entrevistas, a diarreia foi a enfermidade que possuiu maior redução após a construção das MSD. Anteriormente, apenas $29,41 \%$ das famílias alegaram ter sido raro os casos de diarreia, ao passo que posteriormente esses casos raros subiram para 70,59\%. Uma provável explicação para isso seria o impacto direto que a construção dos módulos sanitários tem em prevenir que crianças fiquem expostas aos agentes infecciosos que antes eram provenientes da defecação a céu aberto.

A esquistossomose e a hepatite viral sofreram reduções menos significativas, no entanto isto pode estar atrelado ao fato dos índices dessas doenças não serem tão expressivos mesmo antes da construção das MSD.

Segundo a Funasa, o critério escolhido para implantação das MSD em Itabaiana ocorreu em função do surto de dengue que assolou o município, o qual mostrou as necessidades de determinadas localidades cujo saneamento básico se tornou emergencial. Em contrapartida, embora a motivação inicial do projeto tenha sido a redução dos índices de dengue, os questionários apontaram um aumento desses índices. Aproximadamente $20 \%$ das famílias disseram ter tido dengue com uma frequência entre 2 a 4 vezes antes da construção das MSD, enquanto esse valor subiu para $35,39 \%$ no período posterior.

Diversos fatores observados durante a pesquisa e que não associados ao esgotamento sanitário podem estar associados a esse aumento. Dentre eles estão o hábito de reservar baldes de água para diversos fins, o fechamento inadequado da tampa das caixas d'água e até a possibilidade de diagnósticos imprecisos no período anterior ao projeto, percebido com o relato das famílias que acreditavam ter tido dengue nesse período, porém, por esta não ser uma doença ainda muito conhecida na região, o diagnóstico pode ter sido outro.

Por fim, pode-se concluir que as Melhorias Sanitárias Domiciliares trouxeram resultados favoráveis. Apesar das intervenções não terem mostrado resultados benéficos no que diz respeito ao propósito ao qual foram definidas (redução dos índices de dengue), estas ações trouxeram vantagens tanto com relação à satisfação e bem-estar dos beneficiados quanto às condições de saúde em geral. 


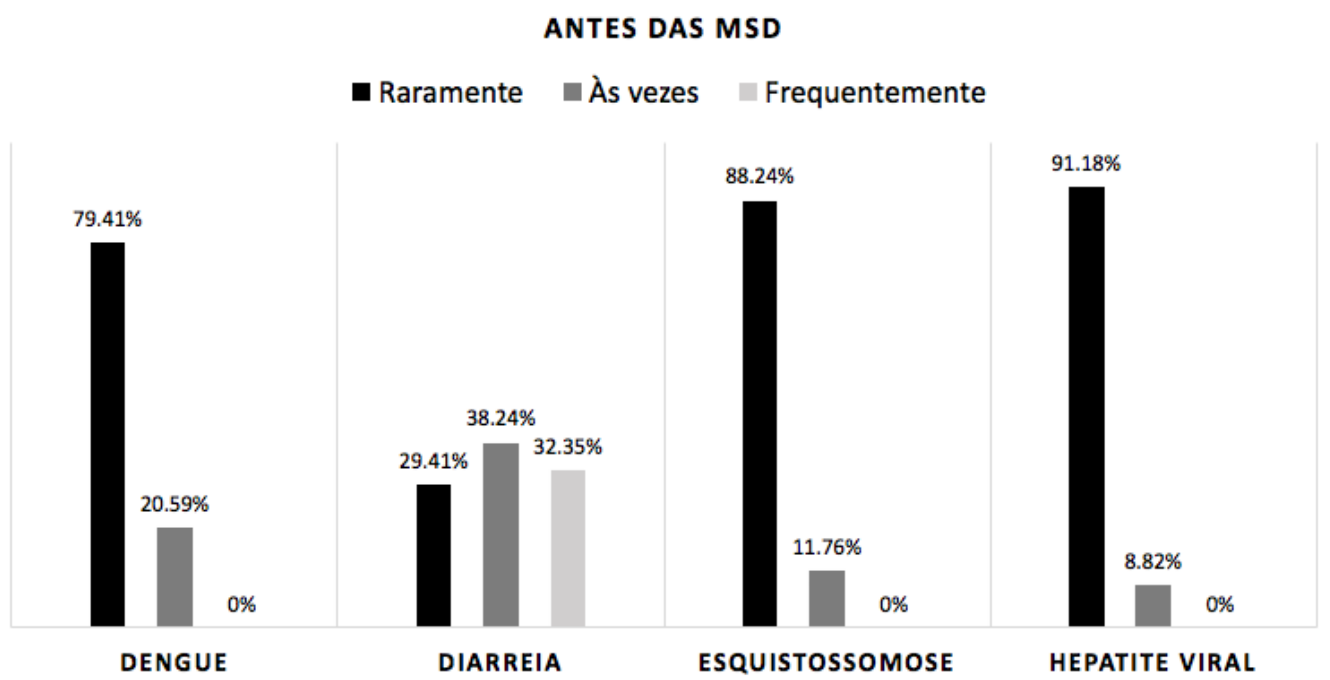

Figura 1: Frequência de doenças infecciosas e parasitárias antes da implantação das MSD segundos relatos da população objetivo

DEPOIS DAS MSD

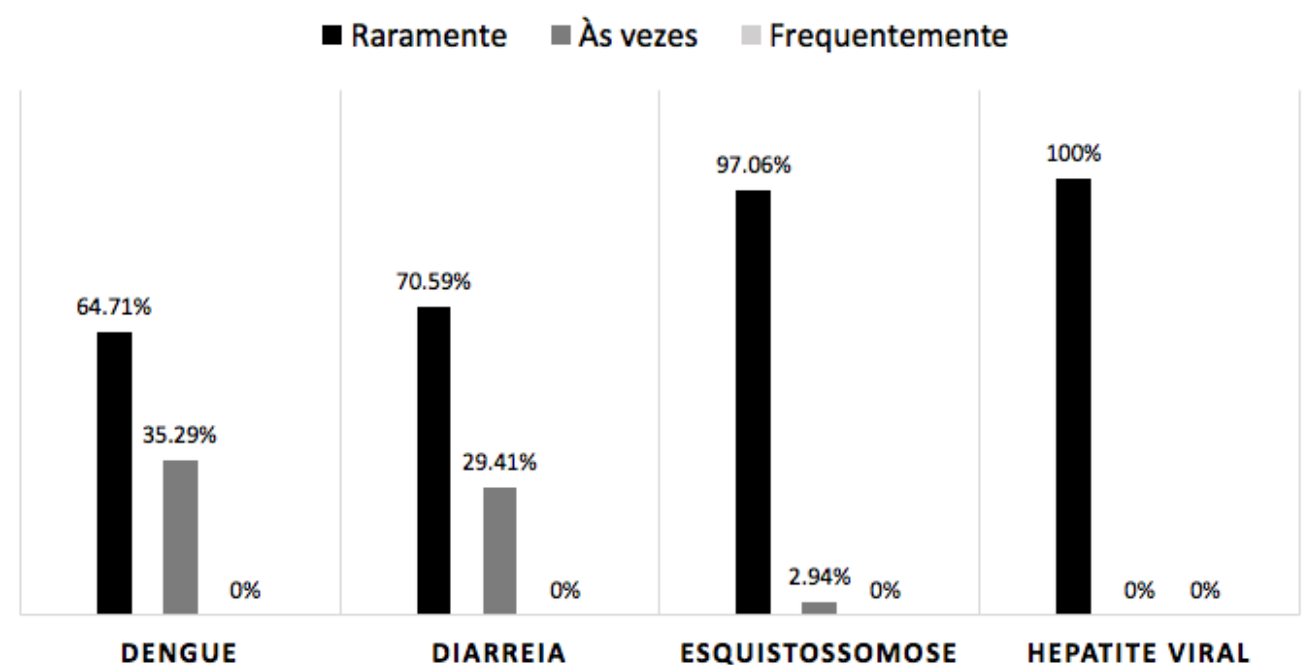

Figura 2: Frequência de doenças infecciosas e parasitárias depois da implantação das MSD segundos relatos da população objetivo

\section{CONCLUSÃO}

A partir da análise dos dados concluiu-se que o programa MSD, desenvolvido pela Funasa, foi satisfatório quanto à redução dos índices de grande parte das doenças infecciosas e parasitárias antes comumente presentes nas comunidades. Embora as taxas de dengue tenham aumentado, contrariando o objetivo do programa, esses índices puderam ser questionados pela população, que relataram ter tido os sintomas da dengue antes da implantação dos módulos sanitários, porém, talvez não foram diagnosticados com essa doença devido à falta de exames adequados que possibilitassem esse diagnóstico. Ademais, os índices de esquistossomose, hepatite viral e, principalmente, diarreia, reduziram significativamente e as famílias se mostraram amplamente satisfeitas com as intervenções, indicando para uma melhora tanto no bem-estar como para a saúde da população objetivo. 


\section{AGRADECIMENTOS}

À Fundação Nacional de Saúde, Funasa, seção Sergipe, pela assistência, disponibilidade e atenção desde o início da pesquisa até a análise e discussão dos resultados.

Ả Fundação de Apoio à Pesquisa e à Inovação Tecnológica do Estado de Sergipe, FAPITEC/SE, pela bolsa de mestrado.

\section{REFERÊNCIAS BIBLIOGRÁFICAS}

1. Guimarães AJA, Carvalho DF, Silva LDB. Saneamento básico [Internet]. Rio de Janeiro (RJ): Universidade Federal Rural do Rio de Janeiro; 2007 [citado em 2016]. Disponível em: http://www.ufrrj.br/institutos/it/deng/leonardo/downloads/APOSTILA/Apostila\%20IT\%20179/Cap\%20 1.pdf.

2. Heller L. Relação entre saúde e saneamento na perspectiva do desenvolvimento. SciELO. 1998;3(2):7384, doi:1413-8123/ISSN.

3. Oliveira S, Simões C. Meio ambiente urbano: mortalidade na infância, saneamento básico e políticas públicas. XV Encontro Nacional de Estudos Populacionais; 2006 Set 18 - Set 22; Caxambú, Minas Gerais. Brasil: ABEP; 2006.

4. Funasa. Manual de Orientações Técnicas para Elaboração de Propostas para o Programa de Melhorias Sanitárias Domiciliares: Funasa. Brasília: Fundação Nacional de Saúde; 2014.

5. DATASUS - Informações de saúde (TABNET) [Internet]. Brasil: Departamento de Informática do Sistema Único de Saúde. 2016 - [citado 2016 Abr 15]. Disponível em: http://www2.datasus.gov.br/DATASUS/index.php?area=0201.

6. IBGE [Internet]. Brasil: Instituto Brasileiro de Geografia e Estatística. 2010 - [citado 2016 Abr 14]. Disponível em: http://cidades.ibge.gov.br/xtras/perfil. php?lang=\&codmun $=280290 \&$ search $=\|$ infogr\%E1ficos:-informa\%E7\%F5es-completas $>$. Acesso em: 14 abr. 2016.

7. Triola MF. Introdução à Estatística. Rio de Janeiro: LTC; 2005. 276 p.

8. Barbetta PA. Estatística aplicada às ciências sociais, 6. ed. Florianópolis: UFSC; 2006.

9. WHO - World Health Organization - 2013 update [Internet]. Genebra, Suiça: World Health Organization; c2013 - [citado 2017 Mar 22]. Disponível em: http://apps.who.int/iris/bitstream/10665/81245/1/9789241505390_eng.pdf. 